\title{
EDUCAÇÃO AMBIENTAL NA ESCOLA: DO PAPEL À REALIDADE - DO DISCURSO AO COMPROMETIMENTO
}

\author{
Vera Aparecida Monteiro Silva de Abrantes ${ }^{1}$ \\ Maria Geralda de Miranda ${ }^{2}$ \\ Carlos Alexandre Bastos de Vasconcellos ${ }^{3}$
}

Resumo: Pretende-se neste artigo expor algumas reflexões acerca das definições, da importância e da aplicabilidade da educação ambiental na Educação Básica, a partir de práticas desenvolvidas no Colégio Pedro II Campus São Cristóvão III, localizado na cidade do Rio de Janeiro. A urgência por encontrar soluções que reduzam os efeitos devastadores da ação do homem sobre o meio natural, buscando um equilíbrio entre o desenvolvimento e a preservação do meio ambiente, traz para o debate as questões relacionadas à sustentabilidade e à educação ambiental. As experiências bem sucedidas aplicadas no Colégio em questão voltadas para o desenvolvimento sustentável serão úteis para compreensão das idéias aqui debatidas.

Palavras-chave: Meio ambiente; Desenvolvimento Sustentável; Educação Ambiental.

\footnotetext{
${ }^{1}$ Colégio Pedro II e Centro Universitário Augusto Motta. E-mail: veraaabrantes@oi.com.br

${ }^{2}$ Centro Universitário Augusto Motta. E-mail: desenvolvimentolocal@unisuam.edu.br

${ }^{3}$ Instituto Militar de Engenharia e Centro Universitário Augusto Motta. E-mail: vasconcellos@ime.eb.br Revbea, São Paulo, V.9, N²: 424-435, 2014.
} 


\section{Introdução}

Frente às grandes mudanças climáticas e às catástrofes naturais ocorridas nos últimos tempos, o homem, principal transformador da natureza, parece ter-se reconhecido, também, como o seu maior destruidor. Tal reconhecimento leva à conscientização de que é necessário encontrar modelos de desenvolvimento que, indo além das perspectivas econômicas, preocupemse com a preservação do meio ambiente e com a qualidade de vida da população. É nesse contexto que surge o conceito de desenvolvimento sustentável, voltado para a ação prudente do homem sobre a natureza e para o bom uso dos recursos que esta lhe oferece.

O tema da sustentabilidade ganha a cada dia destaque na mídia e adesões nas esferas política e social. A crescente degradação do meio ambiente e as previsões pouco agradáveis de um futuro ameaçador à vida no planeta têm levado órgãos governamentais e não governamentais a pensarem estratégias e ações que busquem minimizar o impacto das atividades humanas sobre a natureza. Nessa busca de soluções para uma infinidade de problemas ambientais, a população vem sendo conclamada a participar de forma ativa de projetos e ações sustentáveis para proteger a vida em nosso planeta. A ação governamental é, certamente, necessária em empreendimentos sustentáveis, mas a participação da população é imprescindível para o sucesso e a eficácia de projetos voltados para a proteção ambiental.

Tal afirmação, já observada por Marcatto (2002), mostra que os problemas ambientais se manifestam em nível local. Em muitos casos, os residentes de um determinado local são, ao mesmo tempo, causadores e vítimas de parte dos problemas ambientais. São também essas pessoas quem mais têm condições de diagnosticar a situação. Convivem diariamente com 0 problema e são, provavelmente, os maiores interessados em resolvê-los.

Entre as diversas ações desenvolvidas para garantir a qualidade e a preservação da vida na Terra, uma é de extrema importância, pois que leva em seu bojo a tomada de consciência e a apreensão de algumas práticas necessárias à consolidação de qualquer projeto que vise a um ambiente sustentável, propício à vida: a educação ambiental.

No meio acadêmico, as pesquisas, os estudos e os projetos voltados para a educação ambiental com vistas à sustentabilidade vêm se intensificando desde o início deste novo século, assim como as publicações que versam sobre a mesma temática. E no Ensino Médio, como são tratados os temas da sustentabilidade e do meio ambiente? Afinal, o que é educação ambiental?

O Governo Federal, através do Decreto № 4.281, regulamentou, em 25 de junho de 2002, a Lei no 9.795, de 27 de abril de 1999. Em 2002, conforme 0 decreto no 4.281, da presidência da República, a Política Nacional de Educação Ambiental passa a ser executada, entre outros órgãos, pelas instituições educacionais públicas e privadas dos sistemas de ensino. 
O Colégio Pedro II (CP2), cuja tradição é motivo de orgulho para o Brasil, constitui um exemplo do que pode fazer uma escola de qualidade em benefício da formação e da conscientização de uma sociedade. Em consonância com o Governo Federal, o CP2 acrescenta ao programa do Ensino Médio Integrado, no ano de 2008, a área de formação Meio Ambiente.

Além da iniciativa de um curso técnico voltado para a formação de alunos aptos a desenvolver atividades de prestação de serviços e atuar em empresas públicas e privadas, o CP2 desenvolve atividades de caráter transversal que esclarecem e conscientizam toda a comunidade escolar quanto às questões ambientais, como é o caso da "Oficina Área Verde", desenvolvida no Campus São Cristóvão III.

\section{Revisão de Literatura}

Desde meados do século passado, o tema da sustentabilidade vem ganhando destaque na mídia e adesões nas esferas política e social. A crescente degradação do meio ambiente e as previsões pouco agradáveis de um futuro ameaçador à vida no planeta têm levado órgãos governamentais e não governamentais a pensarem estratégias e ações que busquem minimizar o impacto das atividades humanas sobre a natureza.

Veiga (2010), apoiando-se nas ideias de Ignacy Sachs, estabelece que a sustentabilidade preocupa-se, sobretudo, em preservar o potencial da natureza enquanto produtora de recursos renováveis e limitar o uso de recursos não renováveis. Dessa forma, a sustentabilidade estaria alicerçada em uma solidariedade sincrônica e diacrônica, quando se preocupa com a atual geração e com a geração futura, respectivamente. O desenvolvimento sustentável também é discutido por Barbosa (2008), que reflete sobre suas definições e ressalta sua importância no contexto atual do desenvolvimento no Brasil.

Frente ao panorama inicialmente traçado, a busca de soluções é urgente e, nesse caminho, a população vem sendo conclamada a participar de forma ativa de projetos e ações sustentáveis para proteger a vida em nosso planeta. A participação da sociedade civil, em colaboração às ações governamentais, é imprescindível para o sucesso e a eficácia de projetos voltados para a proteção ambiental. Em relação a tal participação, Marcatto (2002) afirma que a população local, por viver cotidianamente determinadas situações, é que tem maiores condições de avaliar os problemas e encontrar soluções para eles. Nesse sentido, necessita a população de esclarecimentos, informações e orientações para trabalhar pela não destruição, pela recuperação e pela preservação do meio ambiente para esta e para as futuras gerações.

A preocupação com o futuro ambiental do planeta e a consciência de que tal futuro encontra-se nas mãos de cada indivíduo e da sociedade como um todo impulsionaram a busca de caminhos para embasar e preparar o cidadão para trabalhar pelo meio ambiente. Um dos caminhos encontrados é a 
educação ambiental, pois que esta trás em seu cerne a tomada de consciência e a apreensão de algumas práticas necessárias à consolidação de qualquer projeto que vise a um ambiente sustentável e de ações desenvolvidas para garantir a qualidade e a preservação da vida na Terra.

Muitas são as considerações acerca da educação ambiental, como muitos são os conceitos a ela atribuídos e diversas as dúvidas em torno de sua aplicabilidade. Uma simples e importante contribuição no sentido de maiores esclarecimentos sobre a temática em pauta vem de Reigota (2009), em uma publicação preocupada com a difusão da educação ambiental no Brasil e voltada para o reposicionamento da mesma como educação política. Essa perspectiva é compartilhada por Jacobi (2003), que considera a educação ambiental um ato político com vistas à transformação social.

Paralelamente, Mendes e Vaz (2009) discutem o papel da educação básica em relação à educação ambiental e consideram que, embora não se configure em uma disciplina escolar, a educação ambiental pode ser trabalhada por iniciativa e cooperação do corpo docente.

Em consonância com o pensamento anterior, Rizzo (2005) considera que educação ambiental não se caracteriza como uma disciplina a ser ensinada na escola. $O$ autor a vê como um caminho para o desenvolvimento da consciência ambiental, ajudando as pessoas a compreenderem a conjugação de processos (naturais, sociais e econômicos) que afetam o meio ambiente e a se posicionarem com responsabilidade na busca de soluções.

\section{Metodologia}

Dentro do atual contexto de nossa realidade, a temática da sustentabilidade está fortemente presente e traz à luz das discussões a questão da educação ambiental. Pela contemporaneidade de tais assuntos e pela praticidade dada à investigação dos mesmos, escolheu-se como metodologia para este artigo observação e análise de documentos e de literatura voltada para o referido assunto. Para verificar a viabilidade da implantação da educação ambiental no âmbito da educação formal, optou-se por observar o currículo e as práticas de educação ambiental em uma escola do Ensino Médio.

Nesse sentido, é importante ressaltar que se pretende, aqui, discutir por que são tão necessárias, nos tempos atuais, as práticas de ações sustentáveis e como tais práticas podem, através da educação ambiental desenvolvida na escola, passar a integrar o cotidiano de cada indivíduo e de cada comunidade.

O problema aqui observado é como desenvolver a educação ambiental dentro da escola, quer formando cidadãos cientes de seu papel na busca de um ambiente saudável, quer formando profissionais capazes de atuar diretamente em ações ou projetos sustentáveis. 
A escola escolhida para observação é o do Campus São Cristóvão III, do Colégio Pedro II, localizado na Zona Norte do Rio de Janeiro, observando as dificuldades encontradas e os esforços empenhados para desenvolver a consciência da preservação ambiental e comportamentos dessa mesma natureza.

\section{Sustentabilidade e meio ambiente}

Foi na década de 1970 que começou a surgir a concepção de um desenvolvimento dito sustentável, que, agregando crescimento econômico, equidade social e proteção ambiental, promovesse um novo paradigma de desenvolvimento a ser urgentemente adotado.

Segundo Veiga (2010), a sustentabilidade ambiental é baseada no duplo imperativo ético de solidariedade sincrônica com a geração atual e de solidariedade diacrônica com as gerações futuras, dessa forma, cabe a cada geração a responsabilidade de promover e manter, para as próximas gerações, a harmonia entre os campos social, ambiental e econômico, congregação fundamental à vida no planeta.

É no relatório de Brundtland (Comissão Mundial para o Meio Ambiente e Desenvolvimento), publicado em 1987, que o desenvolvimento sustentável aparece ligado à questão das gerações presente e futura, enfatizando a necessidade de novos modelos de desenvolvimento econômico que não agridam o meio ambiente e não esgotem os recursos naturais.

Crescer economicamente sem causar danos irreversíveis à vida, preocupar-se com a diminuição das desigualdades sociais e responsabilizar-se pela conservação ambiental são atitudes fundamentais para o desenvolvimento sustentável, que, na visão de Barbosa (2008) consiste em encontrar meios de produção, distribuição e consumo dos recursos existentes de forma mais coesiva, economicamente eficaz e ecologicamente viável.

É sob a perspectiva de uma imediata mudança de postura nas relações entre o homem e o meio ambiente que:

A reflexão sobre as práticas sociais, em um contexto marcado pela degradação permanente do meio ambiente e do seu ecossistema, cria uma necessária articulação com a produção de sentidos sobre educação ambiental. A dimensão ambiental configura-se crescentemente como uma questão que diz respeito a um conjunto de atores do universo educativo, potencializando o envolvimento dos diversos sistemas de conhecimento, a capacitação de profissionais e a comunidade universitária numa perspectiva interdisciplinar. (JACOBI, 2003, p.189) 
crescem, a economia prospera em alguns meios, o consumo aumenta, assim como a produção de lixo, as desigualdades sociais acentuam-se, gerando a exclusão, os recursos naturais são utilizados pelo homem de forma descompromissada e irresponsável.

Diante deste contexto, medidas urgentes devem ser tomadas, e uma das mais importantes é a conscientização do homem. Reconhecendo-se como potencial responsável pelos problemas que o planeta enfrenta e entendendo o seu papel fundamental para a reversão deste quadro, o homem passa a buscar ações que gerem soluções para estabelecer um convívio de respeito e equilíbrio com o meio ambiente. A educação ambiental assume, nesse cenário, importante função esclarecedora e promotora de atitudes conscientes para cuidar da vida na Terra, preservando-a para aqueles que a herdarão no futuro.

\title{
Educação ambiental
}

O conceito de educação ambiental aparece assim definido no artigo $1^{\circ}$ ำ da Lei no 9795/99:

\begin{abstract}
Entendem-se por educação ambiental os processos por meio dos quais o indivíduo e a coletividade constroem valores sociais,conhecimentos, habilidades, atitudes e competências voltadas para a conservação do meio ambiente, bem de uso comum do povo, essencial à sadia qualidade de vida e sua sustentabilidade. (Lei 9795/1999)
\end{abstract}

A preocupação com um modelo de desenvolvimento sustentável leva o Estado e a sociedade a buscarem caminhos para sua viabilidade. A educação ambiental é vista como um desses caminhos, já que estimula a tomada de consciência e a apreensão de algumas práticas necessárias à consolidação de qualquer ação voltada para o equilíbrio entre o crescimento econômico e a manutenção de um ambiente sustentável, reunindo práticas que venham a garantir a qualidade e a preservação da vida na Terra.

Reigota (2009) ressalta que o surgimento da educação ambiental tem relação direta com conferências mundiais e com movimentos sociais em todo o mundo. São inúmeros os documentos gerados de encontros organizados com a preocupação de proteger o meio ambiente, discutir a sustentabilidade e estabelecer caminhos estruturados para a educação ambiental, como a Carta de Belgrado (1975), Algumas Recomendações da Conferência Intergovernamental sobre Educação Ambiental: Tbilissi, o Capítulo 36 da Agenda XXI, o Tratado de Educação Ambiental Para Sociedades Sustentáveis, a Declaração de Brasília para a Educação Ambiental feita na I Conferência Nacional de EA, a Declaração de Thessaloniki, a Carta da Terra, o Compromisso de Goiânia e a Carta de Itajaí, entre outros.

Órgãos governamentais e não governamentais passaram a se preocupar com a preservação do ambiente natural, com a conscientização e 
com a preparação do indivíduo para cuidar da vida na Terra, no presente, e garantir condições de vida às gerações futuras.

Através do decreto no 4.281/2002 regulamentou-se a lei 9.795/1999, que institui a Política Nacional de Educação Ambiental. Integrando várias providências, o decreto torna responsáveis pela execução da política de educação ambiental as instituições de ensino públicas e privadas, entre outros órgãos. Os PCNs são recomendados como referencial para a inclusão da Educação Ambiental em todos os níveis e modalidades de ensino, fundamentalmente no que diz respeito à integração transversal com todas as disciplinas. O Decreto estabelece, ainda, a criação, a manutenção e a implementação de programas de educação ambiental engajados a todos os níveis e modalidades de ensino.

Em atendimento às leis voltadas preocupadas com a educação ambiental, as esferas federal, estadual e municipal de educação passam a criar, implementar e promover ações, projetos organizados em documentos fundamentados pelas diretrizes do Governo Federal.

\section{Implantação da Educação Ambiental no Colégio Pedro II}

O Colégio Pedro II (CP 2), em consonância com os procedimentos estabelecidos pelo Governo Federal, passou a incluir em suas práticas educativas, ações e projetos voltados para o meio ambiente. Em 2007, acrescentou ao programa do Ensino Médio Integrado a área de formação Meio Ambiente.

Os Parâmetros Curriculares Nacionais revelam uma preocupação com uma educação voltada para o desenvolvimento da cidadania. Dessa forma, incluem entre as práticas pedagógicas da escola a exploração de temas transversais, elegendo as seguintes temáticas: Ética, Meio Ambiente, Pluralidade Cultural, Saúde e Orientação Sexual.

Contemplando as necessidades do momento atual e em conformidade com determinações legais, o CP 2 passou a desenvolver em seus vários Campi projetos e atividades informais de incentivo à preservação do meio ambiente, como a instalação de lixeiras diferenciadas, gincanas de recolhimento de material reciclável, plantio de árvores raras e criação de hortas.

Particularmente, o Campus São Cristóvão III, foi contemplado como locus de duas importantes ações caracterizadas pela preocupação com as condições ambientais do planeta e com a sustentabilidade: a implantação do Ensino Médio Integrado em Meio Ambiente e o Projeto Área Verde.

Apesar das adversidades encontradas - falta de verbas, insuficiência de profissionais, dificuldades em firmar parcerias, entre outras tão comuns na esfera pública -, ० CP 2, cuja missão, explicitada em seu Plano Político Pedagógico, é educar para tornar crianças e adolescentes capazes de responder às transformações técnicas, emocionais e sociais do mundo atual, implantou, em 2007, o Curso Técnico Integrado de Meio Ambiente. 
A educação profissional ministrada no CP 2 integra os saberes das áreas comuns aos saberes específicos das áreas técnicas, oferecendo ao aluno uma formação profissional de qualidade. Segundo a Jornada de Meio Ambiente no Colégio Pedro II: transversalidade para a Educação Ambiental, o Ensino Médio em Meio Ambiente tem como objetivos:

- desenvolver atividades de ensino, pesquisa e extensão na área ambiental transformando o Colégio Pedro II em polo regional de referência em questões ambientais;

- atuar nas esferas da educação,da preservação e da recuperação ambiental;

- capacitar profissionais críticos e aptos a intervir na busca de soluções para os problemas ambientais;

- qualificar recursos humanos para desempenhar funções técnicas, educativas e administrativas ligadas à área ambiental;

- desenvolver nos alunos a capacidade empreendedora como alternativa para inserção no mercado de trabalho; e

- preparar os alunos para o trabalho em equipe, desenvolvendo a capacidade de liderança e o discernimento para a tomada de decisões.

A fim de alcançar os objetivos propostos pelo curso, sua grade curricular é composta pelas seguintes disciplinas específicas: Fundamentos de Meio Ambiente, Estudos Geoambientais e Noções de Ecoturismo, Química Analítica, Metodologia da Pesquisa, Legislação Ambiental, Monitoramento Ambiental, Preservação Ambiental, Estudos de Impactos Ambientais e Manejos de Sistemas Aquáticos e Terrestres.

Desde 2009, o colégio já promoveu quatro jornadas de Meio Ambiente, envolvendo os alunos do curso, os professores e alguns convidados. As jornadas promoveram a integração escola-comunidade-universidade, ampliando as experiências de aprendizagem dos discentes através do contato com saberes e iniciativas diferenciadas. Foram temas das jornadas Que planeta queremos?(2009), Precisamos cuidar do planeta (2010), Gerenciando os recursos ambientais (2010) e Pegada ecológica: que marca deixar? (2012).

Paralelamente ao Curso de Meio Ambiente do Ensino Médio, o Campus São Cristóvão III, do CP2, mantém um projeto que envolve os departamentos de Biologia, História e Artes Visuais. O projeto é aberto aos alunos de todas as séries do Ensino Médio e de todos os Campi do Colégio.

O Programa de Iniciação à Pesquisa Científica, como é intitulado o projeto, é realizado no espaço Área Verde, no Campus São Cristóvão e conta com convênios e colaborações do Jardim Botânico, da Embrapa Solos, da Pontifícia Universidade Católica (PUC-Rio), da Fundação Osvaldo Cruz (FIOCRUZ) e da Universidade Federal Fluminense (UFF).

O Projeto Área Verde, segundo a Professora Lygia Vuyk de Aquino, chefe do Departamento de Biologia e Ciências e atual coordenadora do projeto, desenvolve-se por meio das oficinas de manejo e conservação de áreas 
verdes, que integra toda a comunidade escolar, seja no apoio ou na divulgação dos trabalhos desenvolvidos.

De acordo com descrição publicada na página oficial do Colégio Pedro II, "Este projeto, que buscava inicialmente a recuperação dos $9.000 \mathrm{~m}^{2}$ do Horto Botânico (uma das poucas áreas com cobertura verde no bairro de São Cristóvão), veio" ao encontro dos "anseios de uma educação participativa na área da preservação ambiental, integrando ciência, cultura, arte e cidadania."

As atividades desenvolvidas na oficina são de estudo e recuperação do solo com técnicas de compostagem (ver Figura 1), plantio e técnicas de cultivo de hortaliças, ervas aromáticas e plantas medicinais (ver Figura 2), oficina de cerâmica (ver Figura 3) - desenvolvida no Ateliê da Terra, integrando Ciência, Arte e Pesquisa - e educação ambiental. A terra obtida na prática da compostagem abastece todos os Campi do Colégio, seja para o plantio de jardins ou hortas.

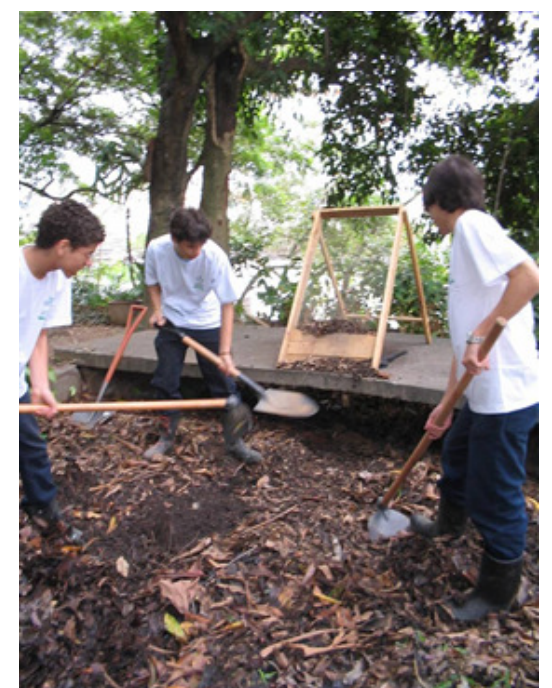

Figura 1: Compostagem. Fonte: Aquino (2012) ${ }^{4}$.

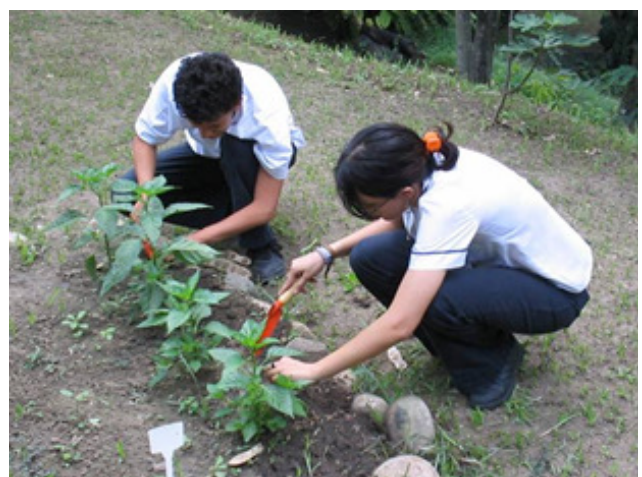

Figura 2: Plantio de hortaliças. Fonte: Aquino (2012) ${ }^{4}$.

${ }^{4}$ Fotografias cedidas por Lygia Vuyk Aquino, Professora do Colégio Pedro II, apresentadas no Seminário Nacional do Ensino Médio: Construindo a Política de Ensino Médio para Todos no Brasil, Brasília, junho de 2012.

Revbea, São Paulo, V.9, №2: 424-435, 2014. 


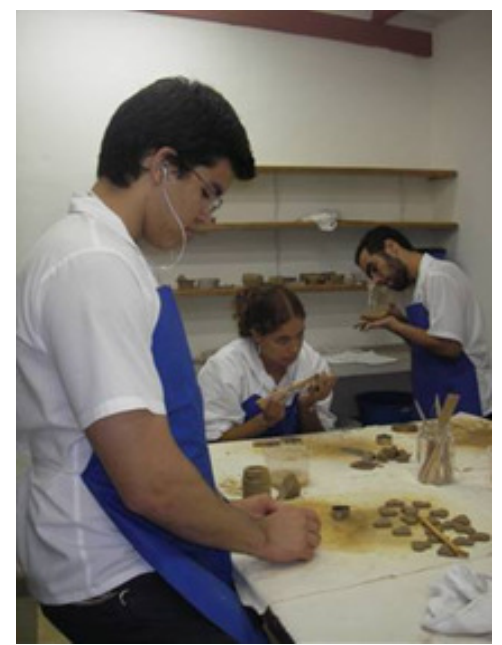

Figura 3: Oficina de cerâmica. Fonte: Aquino (2012) ${ }^{4}$.

A Área Verde do Campus São Cristóvão, além de espaços para plantio, estudos do solo e oficina de artesanato, é constituída por uma sala a céu aberto mostrada na Figura 4 e dois lagos artificiais, sendo que um deles pode ser observado na Figura 5.

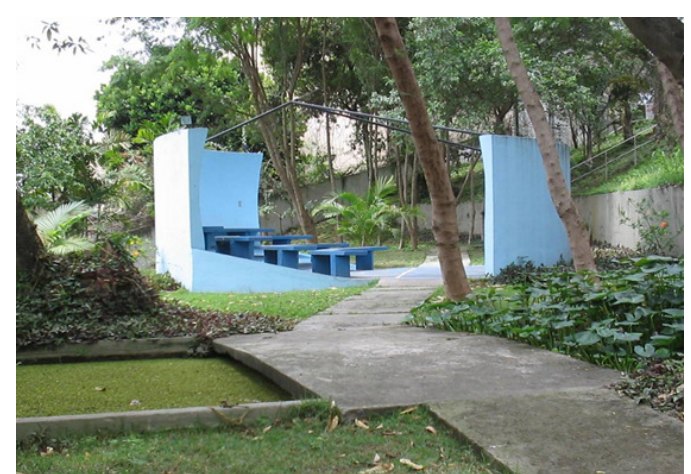

Figura 4: Sala a céu aberto. Fonte: Aquino (2012) ${ }^{4}$.

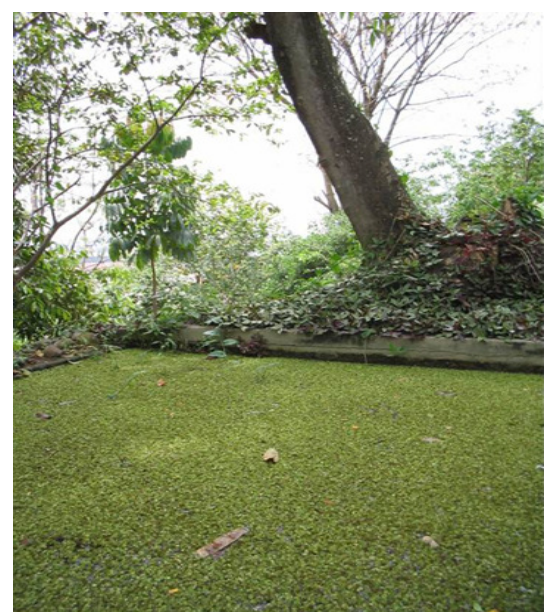

Figura 5: Lago artificial. Fonte: Aquino (2012) ${ }^{4}$.

Revbea, São Paulo, V.9, N²: 424-435, 2014. 
As duas iniciativas do Colégio Pedro II, desenvolvidas no Campus São Cristóvão III - o Ensino Médio em Meio Ambiente e o Projeto Área Verde - em conformidade com o estabelecido pelo Governo Federal no tocante à educação ambiental, estão voltados para a formação da consciência ambiental do educando, adotando práticas sustentáveis e de respeito à capacidade natural do meio ambiente. Além de trabalhar de forma integradora com diferentes áreas do saber.

\section{Considerações finais}

O meio ambiente é um bem de uso comum e é essencial à boa qualidade de vida no planeta. O equilíbrio ecológico do meio ambiente é fundamental nesse sentido. As profundas transformações sofridas pela natureza em função da ação do homem acabaram por despertar, nesse mesmo homem, a percepção da destruição e a consciência da necessidade de preservação de bem tão essencial.

A partir da tomada de consciência sobre a necessidade de proteger 0 meio ambiente, o homem começou a perceber que o desenvolvimento desenfreado em busca do crescimento econômico precisava ser repensado. Essa reflexão resultou na concepção do desenvolvimento sustentável, ou seja, promover o desenvolvimento e o crescimento econômico sem descuidar do meio ambiente, mantendo-o saudável para as futuras gerações.

Alcançar o desenvolvimento sustentável, protegendo a natureza da ação humana, demanda tempo, informação, conscientização e mudança de atitudes. Nesse sentido, a educação ambiental assume importante função, esclarecendo e promovendo atitudes conscientes para cuidar da vida na Terra, preservando-a para aqueles que a herdarão no futuro.

A educação ambiental não está restrita apenas ao ambiente escolar, mas, certamente deve estar presente neste universo, permeando as diversas disciplinas e todas as atividades desenvolvidas no âmbito escolar.

São inúmeras as dificuldades enfrentadas pelas escolas para integrar ao seu cotidiano atividades e projetos que desenvolvam a educação ambiental. Embora a Política Nacional de Educação Ambiental surja como uma exigência do Governo Federal, a escassez de verbas, a falta de profissionais preparados, a dificuldade de promover mudanças no currículo e tantos outros empecilhos acabam por inviabilizar a implantação da educação ambiental nas escolas.

O Colégio Pedro II, comprometido com a missão de formar cidadãos capazes de responder às mudanças do mundo atual, mostra que é possível levar para o âmbito da escola a educação ambiental, voltada para o desenvolvimento sustentável. Quer em curso oficial de formação profissional, quer em projeto aberto a alunos do Ensino Médio, em geral, o colégio investe na formação da consciência ecológica de seu corpo discente e no desenvolvimento de sua capacidade de tomar decisões necessárias ao desenvolvimento sustentável.

Revbea, São Paulo, V.9, N²: 424-435, 2014. 


\section{Agradecimentos}

À Coordenação de Aperfeiçoamento de Pessoal de Nível Superior (CAPES) pelo apoio financeiro à pesquisa através do projeto AMBENAP/OBEDUC/CAPES, desenvolvido pelo Programa de Pós-Graduação em Desenvolvimento Local da UNISUAM.

\section{Referências}

ÁREA VERDE: O programa - Histórico - Oficina. Disponível em: http://www.cp2.g12.br. Acesso em: 15/12/2012

BARBOSA, G.S. O desafio do desenvolvimento sustentável. Revista Visões, 4를 Edição, №4, Volume 1, 2008.

COLÉGIO PEDRO II. Colégio Pedro II: projeto político-pedagógico. Brasília: Inep/MEC, 2002, $400 \mathrm{p}$.

JACOBI, P. Educação ambiental, cidadania e sustentabilidade. Cadernos de Pesquisa, n. 118, março/ 2003. Disponível em http://www.scielo.br/pdf/cp/n118/16834.pdf

MARCATTO, C. Educação ambiental: conceitos e princípios. Belo Horizonte: FEAM, 2002.

MENDES, R.; VAZ, A. Educação ambiental no ensino formal: narrativas de professores sobre suas experiências e perspectivas. 2009. http://www.scielo.br/pdf/edur/v25n3/19.pdf

REIGOTA, M. O que é educação ambiental. São Paulo: Brasiliense, 2009.

RIZZO, J.F.. Educação Ambiental ou Educação Ambiental. 2005. Disponível em http://www3.mg.senac.br/Revistasenac/edicoes/edicao3.htm

VEIGA, J.E. Desenvolvimento sustentável: o desafio do século XXI. Rio de Janeiro: Garamond, 2010. 